\title{
Significant functional tricuspid regurgitation portends poor outcomes in patients with atrial fibrillation and preserved left ventricular ejection fraction
}

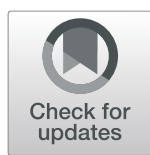

Natthaporn Prapan ${ }^{1}$, Nithima Ratanasit ${ }^{1^{*}}$ (1) and Khemajira Karaketklang ${ }^{2}$

\begin{abstract}
Background: Significant tricuspid regurgitation (TR) can be found in patients with atrial fibrillation (AF). The results of previous studies are controversial about whether significant functional TR (FTR) in patients with AF leads to worse clinical outcomes. The aims of the study were to investigate the prevalence, predictors and prognosis of significant FTR in patients with AF with preserved left ventricular ejection fraction (LVEF).

Methods: The present study was a retrospective cohort study in patients with AF and preserved LVEF from May 2013 through January 2018. Significant FTR was defined as moderate to severe TR without structural abnormality of the tricuspid valve. Pulmonary hypertension $(\mathrm{PH})$ was defined as pulmonary artery systolic pressure $\geq 50 \mathrm{mmHg}$ or mean pulmonary artery pressure $\geq 25 \mathrm{mmHg}$ determined by echocardiography. The adverse outcomes were defined as heart failure and death from any cause within 2 years of follow up.

Results: A total of 300 patients with AF (mean age $68.8 \pm 10.8$ years, $50 \%$ male) were included in the study. Paroxysmal and non-paroxysmal AF were reported in 34.7 and $65.3 \%$ of patients, respectively. Mean LVEF was $65.3 \pm 6.3 \%$. PH and significant FTR were observed in 31.3 and $21.7 \%$ of patients, respectively. Patients with significant FTR were significantly older, more female gender and non-paroxysmal AF, and had higher left atrial volume index and pulmonary artery pressure than those without. A total of $26(8.7 \%)$ patients died and heart failure occurred in 39 (13.0\%) patients. There was a statistically significant difference in the adverse outcomes between patients with significant and insignificant FTR (44.6\% vs. 11.9\%, $p<0.010)$. Multivariable analysis showed that factors associated with significant FTR were female gender, presence of PH and left atrial volume index $(\mathrm{OR}=2.61,1.87$, and 1.04, respectively). The predictors of the adverse outcomes in patients with AF were significant FTR, presence of $\mathrm{PH}$ and high $\mathrm{CHA}_{2} \mathrm{DS}_{2}-\mathrm{VASC}$ score $(\mathrm{OR}=5.23,2.23$ and 1.60, respectively).

Conclusions: Significant FTR was common in patients with AF, and independently associated with adverse outcomes. Thus, comprehensive echocardiographic assessment of FTR in patients with AF and preserved LVEF is fundamental in determining the optimal management.
\end{abstract}

Keywords: Atrial fibrillation, Functional tricuspid regurgitation, Left atrial volume, Prognosis, Pulmonary hypertension, Severe tricuspid regurgitation

\footnotetext{
* Correspondence: nithma.cha@mahidol.ac.th

'Division of Cardiology, Department of Medicine, Faculty of Medicine, Siriraj Hospital, Mahidol University, Bangkok 10700, Thailand

Full list of author information is available at the end of the article
}

(c) The Author(s). 2020 Open Access This article is licensed under a Creative Commons Attribution 4.0 International License, which permits use, sharing, adaptation, distribution and reproduction in any medium or format, as long as you give appropriate credit to the original author(s) and the source, provide a link to the Creative Commons licence, and indicate if changes were made. The images or other third party material in this article are included in the article's Creative Commons licence, unless indicated otherwise in a credit line to the material. If material is not included in the article's Creative Commons licence and your intended use is not permitted by statutory regulation or exceeds the permitted use, you will need to obtain permission directly from the copyright holder. To view a copy of this licence, visit http://creativecommons.org/licenses/by/4.0/ The Creative Commons Public Domain Dedication waiver (http://creativecommons.org/publicdomain/zero/1.0/) applies to the data made available in this article, unless otherwise stated in a credit line to the data. 


\section{Background}

Atrial fibrillation (AF) occurs commonly, especially with advancing age, and it is increasingly recognized as the leading cause of cardiovascular morbidity and mortality [1-3]. AF per se leads to atrial and annular dilation despite normal ventricular systolic function and size, and subsequently, secondary or functional mitral regurgitation and/or tricuspid regurgitation (TR) [4-6]. Moderate to severe functional TR (FTR) is becoming a major concern in patients with AF since it may lead to progressive right ventricular (RV) dilatation and failure, and an increase in morbidity and mortality. The prevalence of significant FTR in patients with AF varies among different studies, ranging from 5 to 35\% [7-10]. A large number of previous studies have shown the association between AF and atrial functional mitral regurgitation, and its prognostic value, while only a few studies have focused on significant atrial FTR. Abe et al. showed that the prevalence of significant FTR increased with the longer duration of $\mathrm{AF}$ and was associated with poor prognosis [9]. In contrast, Takahashi et al. reported a favorable prognosis of severe isolated TR associated with AF [7]. Therefore, the prognostic significance of FTR in patients with AF remains unsettled. The objectives of the present study were to study the prevalence and the predictors of significant FTR in patients with AF with preserved left ventricular ejection fraction (LVEF) as well as to investigate the association of FTR with the adverse outcomes.

\section{Methods}

\section{Study population}

This is a retrospective cohort study of patients with AF and preserved LVEF who underwent a comprehensive echocardiographic examination at Siriraj Hospital from May 2013 through January 2018. The Siriraj Institutional Review Board, Siriraj Hospital, Mahidol University (Bangkok, Thailand) approved the study protocol. The clinical characteristics, follow-up data, electrocardiographic and echocardiographic data were collected from medical records and echocardiography laboratory database. The inclusion criteria were patients who were 18 years or older, the diagnosis of AF from either electrocardiograpm or Holter monitoring, preserved LVEF $(\geq$ $50 \%)$ and complete follow-up data for at least 2 years. Patients with the diagnosis of heart failure at the time of echocardiography, primary TR, concomitant moderate or greater degree of primary left-sided valvular disease, prosthetic valve, permanent pacemaker, cardiomyopathy, prior cardiac device implantation or cardiac surgery, history of coronary artery disease or myocardial infarction or regional wall motion abnormality on echocardiography, chronic pulmonary disease or patients with incomplete data were excluded. AF was classified as paroxysmal and non-paroxysmal. Non-paroxysmal AF included persistent and permanent AF. $\mathrm{CHA}_{2} \mathrm{DS}_{2}$-VASc score for estimating risk of stroke was calculated as previously described [11]. During the follow-up, data regarding heart failure, cardiac and non-cardiac death were recorded. Heart failure was defined as heart failure visit or hospitalization. The adverse outcomes included heart failure visit or hospitalization, and death from any cause.

\section{Echocardiography}

All echocardiographic measurements were performed according to the standard guidelines and obtained by averaging at least 5 consecutive beats. The LVEF, left ventricular (LV) dimensions, LV mass and left atrial volume (LAV) were determined according to the standard methods $[12,13]$. Significant FTR was defined as moderate to severe TR without structural abnormality of tricuspid valve. The severity of FTR was determined using the combination of multiple parameters, including the assessment of vena contracta, color Doppler-derived jet area, the density and contour of continuous wave Doppler spectrum, and the hepatic vein flow Doppler pattern [14-16]. Mean pulmonary artery pressure (PAP) and pulmonary artery systolic pressure (PASP) were estimated using continuous-wave Doppler spectra of pulmonary regurgitation and TR jets, respectively [17]. Pulmonary hypertension $(\mathrm{PH})$ was defined as mean $\mathrm{PAP} \geq 25 \mathrm{mmHg}$ and/or PASP $\geq 50 \mathrm{mmHg}$. RV systolic function was assessed by tricuspid annular plane systolic excursion (TAPSE) and peak systolic myocardial velocity of tricuspid valve annulus $\left(\mathrm{S}_{\mathrm{TV}}^{\prime}\right)$. Impaired $\mathrm{RV}$ systolic function was defined as TAPSE $<16 \mathrm{~mm}$ and/or $\mathrm{S}_{\mathrm{TV}}<$ $10 \mathrm{~cm} / \mathrm{s}$ [17].

\section{Statistical analysis}

Descriptive statistics, including frequency and percentage, were used for categorical variables. Continuous variables were reported as mean \pm standard deviation for normally distributed variables and median (percentile 25 and percentile 75) for non-normally distributed variables. Comparisons of categorical variables between patients with significant and insignificant FTR and between patients with and without adverse outcomes were performed using Chi-square test or Fisher's exact test. Continuous variables were compared using Student's t-test. The following variables (age, female gender, non-paroxysmal AF, dyslipidemia, diuretic, LV diastolic dimension index, LAV index, TAPSE and PASP) were analyzed to determine the factors associated with significant FTR. Differences between groups were considered to be significant for the variables with $p$-value $<0.05$ and those variables were further analyzed by multivariate logistic regression (backward stepwise) to determine the independent factors associated with significant FTR and presented as odds ratio ( $95 \%$ confidence interval). The 
affection factors with the adverse outcomes and heart failure outcome were compared using the Log rank test and presented by Kaplan-Meier survival curve. Variables with $p$-value $<0.05$ on the univariate analysis for adverse outcomes (eg. age, female gender, $\mathrm{CHA}_{2} \mathrm{DS}_{2}$-VASc score, history of stroke, history of heart failure, diuretics, LAV index, significant FTR, impaired RV systolic function and $\mathrm{PH}$ ) and for heart failure outcome (female gender, $\mathrm{CHA}_{2} \mathrm{DS}_{2}$-VASc score, history of stroke, history of heart failure, diuretics, LAV index, significant FTR, impaired RV systolic function and $\mathrm{PH}$ ) were further analyzed and included in the multivariate predictors of adverse outcomes and heart failure outcome using the Cox proportional hazard analysis (backward stepwise) and presented as hazard ratios (95\% confidence interval). For all tests performed, a two-tailed $p$-value $<0.05$ was considered to be statistically significant. PASW Statistic (SPSS) 18.0 (SPSS, Inc., Chicago, IL, USA) was used to perform all statistical analyses.

\section{Results}

A total of 498 patients with AF were considered for this study, but after applying the exclusion criteria listed above, 300 patients (mean age $68.8 \pm 10.8$ years, $50.0 \%$ female) were enrolled in the study. Baseline characteristics, echocardiographic data and adverse outcomes in all patients are shown in Table 1.

\section{Patient characteristics}

Non-paroxysmal and paroxysmal AF were reported in 65.3 and $34.7 \%$ of patients, respectively. The mean AF duration was $26.6 \pm 41.3$ months. The mean $\mathrm{CHA}_{2} \mathrm{DS}_{2}$ VASc score was $3.3 \pm 1.7$ (range $0-7$ ). Anticoagulants and aspirin were prescribed in 78.3 and $12.0 \%$ of patients, respectively. Regarding concurrent medications, betablockers, diuretic, digoxin and amiodarone were reported in $71.3,19.3,6.3$ and $3.7 \%$ of patients, respectively.

\section{Echocardiographic data}

$\mathrm{PH}$ and significant FTR were reported in 31.3 and $21.7 \%$ of patients, respectively. About one fourth of the patients (24.3\%) had no TR. The mean PAP and PASP were $23.7 \pm 7.2$ and $38.3 \pm 11.5 \mathrm{mmHg}$, respectively. Impaired RV systolic function was reported in $14.7 \%$ of patients. TAPSE and $S^{\prime}{ }_{T V}$ were $19.5 \pm 3.1 \mathrm{~mm}$ and $11.4 \pm 2.2 \mathrm{~cm} / \mathrm{s}$, respectively.

\section{Outcomes}

The median follow-up duration was 2.82 years (interquartile range $1.96-4.14$ years). Adverse outcomes were observed in $57(19.0 \%)$ of patients. Heart failure occurred in $39(13.0 \%)$ of patients, while 26 (8.7\%) died. No patients suffered a cardiac death. Most deaths were from infectious cause and/or sepsis. Visits and hospitalizations for heart failure occurred in 39 (13.0\%) and $20(6.7 \%)$ patients, respectively.

\section{Comparisons between patients with significant and insignificant tricuspid regurgitation}

Table 1 shows the comparisons between patients with significant and insignificant FTR, in term of baseline characteristics, echocardiographic data and adverse outcomes. History of stroke and heart failure were not significantly different between the two groups. The AF duration was 9.6 and 2.9 months in patients with significant and insignificant FTR, respectively $(p=0.078)$. PH and impaired RV systolic function were more prevalent in patients with significant FTR $(49.2 \%$ vs. $26.2 \%$, $p<0.001$ and $24.6 \%$ vs. $11.9 \%, p=0.010$, respectively).

\section{Comparisons between patients with and without adverse outcomes}

Table 2 shows the comparisons between patients with and without the adverse outcomes. Patients with adverse outcomes were older, more female gender and have higher $\mathrm{CHA}_{2} \mathrm{DS}_{2}$-VASc score and more comorbidities than those without. LVEF and LV dimensions were not significantly different between patients with and without adverse outcomes. There was no statistically significant difference in adverse outcomes between patients with paroxysmal and non-paroxysmal AF (14.4\% vs. $21.4 \%$, $p<0.141)$.

\section{Predictors of significant tricuspid regurgitation}

Table 3 shows the univariate and multivariable predictors of significant FTR in patients with AF. Female gender, LAV index and presence of $\mathrm{PH}$ were independent determinants of significant FTR.

\section{Predictors of adverse outcomes}

Table 4 shows the univariate and multivariable predictors of the adverse outcomes in patients with AF. Significant FTR was the strongest predictor of adverse outcomes. Female gender, presence of PH and significant FTR were independent determinants of heart failure when that was considered as the only adverse cardiovascular outcome (Table 5). On the survival analysis, patients with significant FTR significantly had poorer prognosis that those with insignificant FTR (Fig. 1a and b). The event-free rates from death and heart failure at $1,3,5$, and 7 years were 91.7, 83.3, 76.0 and $65.1 \%$, respectively. The event-free rates from heart failure at $1,3,5$, and 7 years were 92.9, $87.8,85.7$ and $76.3 \%$, respectively.

\section{Discussion}

The present study demonstrates that moderate to severe FTR portends poor prognosis in patients with AF and preserved LVEF, especially in terms of heart failure. 
Table 1 Baseline characteristics, echocardiographic data and outcomes in all patients and the comparisons between patients with significant and insignificant functional tricuspid regurgitation

\begin{tabular}{|c|c|c|c|c|}
\hline Variables & All patients $(n=300)$ & Significant FTR $(n=65)$ & Insignificant FTR $(n=235)$ & $P$-value \\
\hline \multicolumn{5}{|l|}{ Baseline characteristics } \\
\hline Age (years) & $68.8 \pm 10.8$ & $71.3 \pm 10.3$ & $68.1 \pm 10.9$ & 0.034 \\
\hline Female gender & $150(50.0)$ & $45(68.2)$ & $105(44.7)$ & $<0.001$ \\
\hline Non-paroxysmal AF & $196(65.3)$ & $53(81.5)$ & $143(60.9)$ & 0.010 \\
\hline $\mathrm{CHA}_{2} \mathrm{DS}_{2}$-VASc score & $3.3 \pm 1.7$ & $3.6 \pm 1.8$ & $3.2 \pm 1.7$ & 0.103 \\
\hline Hypertension & $235(78.3)$ & $50(76.9)$ & $185(79.1)$ & 0.710 \\
\hline Dyslipidemia & $153(51.0)$ & $24(36.9)$ & $129(54.9)$ & 0.010 \\
\hline Diabetes mellitus & $105(35.0)$ & $17(26.2)$ & $88(37.4)$ & 0.091 \\
\hline History of stroke & $88(29.3)$ & $18(28.1)$ & $70(29.8)$ & 0.796 \\
\hline History of heart failure & $45(15.0)$ & $11(16.9)$ & $34(14.5)$ & 0.624 \\
\hline Diuretics & $58(19.3)$ & $20(30.8)$ & $38(16.2)$ & 0.020 \\
\hline \multicolumn{5}{|l|}{ Echocardiographic data } \\
\hline LVEF (\%) & $65.3 \pm 6.3$ & $63.9 \pm 6.3$ & $65.7 \pm 6.3$ & 0.052 \\
\hline LVDdi $\left(\mathrm{mm} / \mathrm{m}^{2}\right)$ & $25.7 \pm 4.2$ & $26.7 \pm 4.0$ & $25.4 \pm 4.2$ & 0.025 \\
\hline LVSdi $\left(\mathrm{mm} / \mathrm{m}^{2}\right)$ & $16.4 \pm 3.0$ & $17.3 \pm 3.2$ & $16.3 \pm 5.0$ & 0.137 \\
\hline LAV index $\left(\mathrm{ml} / \mathrm{m}^{2}\right)$ & $49.0 \pm 15.6$ & $58.4 \pm 17$ & $46.5 \pm 14.2$ & $<0.001$ \\
\hline TAPSE (mm) & $19.5 \pm 3.1$ & $18.7 \pm 2.7$ & $19.7 \pm 3.1$ & 0.016 \\
\hline $\mathrm{S}_{\mathrm{TV}}^{\prime}(\mathrm{cm} / \mathrm{s})$ & $11.4 \pm 2.2$ & $11.3 \pm 2.5$ & $12.1 \pm 6.9$ & 0.431 \\
\hline RAP (mmHg) & $7.6 \pm 3.4$ & $9.2 \pm 4.2$ & $7.2 \pm 3.0$ & $<0.001$ \\
\hline Mean PAP (mmHg) & $23.7 \pm 7.2$ & $26.8 \pm 8.2$ & $22.7 \pm 6.5$ & 0.002 \\
\hline PASP $(\mathrm{mmHg})$ & $38.3 \pm 11.5$ & $45.0 \pm 14.7$ & $36.3 \pm 9.5$ & $<0.001$ \\
\hline \multicolumn{5}{|l|}{ Outcomes } \\
\hline Death and heart failure & $57(19.0)$ & $29(44.6)$ & $28(11.9)$ & $<0.001$ \\
\hline Heart failure visit & $39(13.0)$ & $24(36.9)$ & $15(6.4)$ & $<0.001$ \\
\hline Heart failure hospitalization & $20(6.7)$ & $9(13.8)$ & $11(4.7)$ & 0.020 \\
\hline Death & $26(8.7)$ & $8(12.3)$ & $18(7.7)$ & 0.240 \\
\hline
\end{tabular}

Data are expressed as number (percentage) and mean \pm standard deviation

Abbreviations: AF atrial fibrillation, FTR functional tricuspid regurgitation, $L A V$ left atrial volume, $L V D d i$ left ventricular diastolic dimension index, $L V E F$ left ventricular ejection fraction, LVSdi left ventricular systolic dimension index, PAP pulmonary artery pressure, PASP pulmonary artery systolic pressure, RAP right atrial pressure,

$S_{T V}^{\prime}$ peak systolic myocardial velocity of lateral tricuspid annulus, TAPSE tricuspid annular plane systolic excursion

Female gender, LAV index and presence of PH were independent predictors of significant FTR. Furthermore, $\mathrm{CHA}_{2} \mathrm{DS}_{2}$-VASc score, significant FTR and presence of $\mathrm{PH}$ were independent predictors of heart failure and death. Interestingly, the presence of $\mathrm{PH}$ was the only parameter in common to predict both significant FTR and adverse outcomes.

\section{Prevalence of significant functional tricuspid regurgitation in patients with atrial fibrillation}

The prevalence of significant FTR in the present study was $21.7 \%$. The reported prevalence of FTR in patients with AF has varied among different studies and depends on several factors, including the size and demographics of the study population, AF duration, the measurement and definition of significant FTR, different echocardiographic techniques (two-dimensional vs. three-dimensional, or transthoracic vs. transesophageal echocardiography) [7-9, 18-20]. Abe et al. demonstrated the relationship between AF duration and the prevalence of significant FTR $(0,17$ and $25 \%$ of patients at $<1,1-10$ and $>10$ years, respectively) [9]. The present study demonstrated that nonparoxysmal AF was more common in patients with significant FTR than those with insignificant FTR, which supports the possible explanation that long-standing AF may lead to right atrial dilatation and eventually, significant atrial FTR.

Importance of significant tricuspid regurgitation and pulmonary hypertension in patients with atrial fibrillation The presence of significant FTR is associated with an increase in morbidity and mortality, regardless of 
Table 2 Comparisons of baseline characteristics and echocardiographic data between patients with and without adverse outcomes

\begin{tabular}{|c|c|c|c|}
\hline Variables & $\begin{array}{l}\text { Adverse outcomes } \\
(n=57)\end{array}$ & $\begin{array}{l}\text { No adverse outcomes } \\
(n=243)\end{array}$ & $P$-value \\
\hline \multicolumn{4}{|l|}{ Baseline characteristics } \\
\hline Age (year) & $71.8 \pm 10.4$ & $68.1 \pm 10.9$ & 0.019 \\
\hline Female gender & $42(73.7)$ & $108(44.4)$ & $<0.001$ \\
\hline Non-paroxysmal AF & $42(73.7)$ & $154(63.4)$ & 0.192 \\
\hline $\mathrm{CHA}_{2} \mathrm{DS}_{2}$-VASc score & $4.3 \pm 1.9$ & $3.0 \pm 1.6$ & $<0.001$ \\
\hline Hypertension & $49(86.0)$ & $186(76.9)$ & 0.132 \\
\hline Dyslipidemia & $26(45.6)$ & $127(52.3)$ & 0.366 \\
\hline Diabetes mellitus & $25(43.9)$ & $80(32.9)$ & 0.119 \\
\hline History of stroke & $27(48.2)$ & $61(25.1)$ & 0.001 \\
\hline History of heart failure & $15(26.3)$ & $30(12.3)$ & 0.008 \\
\hline Diuretics & $25(43.9)$ & $33(13.6)$ & $<0.001$ \\
\hline \multicolumn{4}{|l|}{ Echocardiographic data } \\
\hline Significant FTR & $29(50.9)$ & $36(14.8)$ & $<0.001$ \\
\hline LVEF (\%) & $65.6 \pm 7.5$ & $65.2 \pm 6.0$ & 0.635 \\
\hline LVDdi $\left(\mathrm{mm} / \mathrm{m}^{2}\right)$ & $25.7 \pm 5.9$ & $25.7 \pm 3.7$ & 0.994 \\
\hline LVSdi $\left(\mathrm{mm} / \mathrm{m}^{2}\right)$ & $16.5 \pm 3.6$ & $16.5 \pm 4.9$ & 0.876 \\
\hline LAV index $\left(\mathrm{ml} / \mathrm{m}^{2}\right)$ & $54.0 \pm 16.2$ & $47.9 \pm 15.3$ & 0.008 \\
\hline TAPSE (mm) & $18.6 \pm 2.9$ & $19.7 \pm 3.1$ & 0.027 \\
\hline $\mathrm{S}_{\mathrm{TV}}^{\prime}(\mathrm{cm} / \mathrm{s})$ & $13.5 \pm 13.4$ & $11.5 \pm 2.2$ & 0.073 \\
\hline Impaired RV systolic function & $15(26.3)$ & $29(11.9)$ & 0.006 \\
\hline $\operatorname{RAP}(\mathrm{mmHg})$ & $8.6 \pm 3.9$ & $7.4 \pm 3.2$ & 0.015 \\
\hline Mean PAP (mmHg) & $27.2 \pm 8.5$ & $22.8 \pm 6.5$ & $<0.001$ \\
\hline PASP $(\mathrm{mmHg})$ & $42.9 \pm 13.3$ & $37.1 \pm 10.8$ & 0.001 \\
\hline Pulmonary hypertension & $28(49.1)$ & $64(26.3)$ & 0.001 \\
\hline
\end{tabular}

Data are expressed as number (percentage) and mean \pm standard deviation

Abbreviations: AF atrial fibrillation, FTR functional tricuspid regurgitation, $L A V$ left atrial volume, $L V D d i$ left ventricular diastolic dimension index, $L V E F$ left ventricular ejection fraction, LVSdi left ventricular systolic dimension index, PAP pulmonary artery pressure, PASP pulmonary artery systolic pressure, RAP right atrial pressure, $R V$ right ventricular, $S_{T V}^{\prime}$ peak systolic myocardial velocity of lateral tricuspid annulus, TAPSE tricuspid annular plane systolic excursion

pulmonary pressure and LVEF [21]. FTR is not uncommon and occurs as a result of various underlying diseases, such as left-sided heart disease or PH $[18,19,22]$. Recently, isolated FTR in patients with AF has gained much attention. However, some concerns have arisen regarding the long-term prognostic significance and the optimal management of atrial FTR. Some previous studies reported the favorable short-term prognosis of FTR in patients with AF. For example, Yakahashi et al. demonstrated a good prognosis of idiopathic FTR in patients with AF without structural heart disease and no $\mathrm{PH}$ with the 1-year cumulative mortality and cumulative mortality due to right-sided heart failure of 5 and $1 \%$, respectively [7]. The present study shows that the

Table 3 Univariate and multivariable analyses of factors associated with significant functional tricuspid regurgitation

\begin{tabular}{|c|c|c|c|c|c|c|}
\hline \multirow[t]{2}{*}{ Factors } & \multicolumn{3}{|c|}{ Univariate analysis } & \multicolumn{3}{|c|}{ Multivariable analysis } \\
\hline & OR & $95 \% \mathrm{Cl}$ & $P$-value & OR & $95 \% \mathrm{Cl}$ & $P$-value \\
\hline Age & 1.03 & $1.00-1.06$ & 0.035 & & & \\
\hline Female gender & 2.78 & $1.56-5.00$ & 0.001 & 2.61 & $1.40-4.88$ & 0.003 \\
\hline Non-paroxysmal AF & 2.84 & $1.44-5.60$ & 0.003 & & & \\
\hline LAV index & 1.05 & $1.03-1.07$ & $<0.001$ & 1.04 & $1.01-1.06$ & $<0.010$ \\
\hline Impaired RV systolic function & 2.41 & $2.21-4.80$ & 0.010 & & & \\
\hline Pulmonary hypertension & 2.73 & $1.5-4.82$ & 0.001 & 1.87 & $1.01-3.46$ & 0.046 \\
\hline
\end{tabular}

Abbreviations: $A F$ atrial fibrillation, $C l$ confidence interval, $L A V$ left atrial volume, $O R$ odd ratio, $R V$ right ventricular 
Table 4 Univariate and multivariable analyses of the predictors of death and heart failure

\begin{tabular}{|c|c|c|c|c|c|c|}
\hline \multirow[t]{2}{*}{ Factors } & \multicolumn{3}{|c|}{ Univariate analysis } & \multicolumn{3}{|c|}{ Multivariable analysis } \\
\hline & HR & $95 \% \mathrm{Cl}$ & $P$-value & $\mathrm{HR}$ & $95 \% \mathrm{Cl}$ & $P$-value \\
\hline Age & 1.03 & $1.01-1.06$ & 0.013 & & & \\
\hline Female gender & 3.53 & $1.94-6.42$ & $<0.001$ & & & \\
\hline $\mathrm{CHA}_{2} \mathrm{DS}_{2}$-VASc score & 1.50 & $1.29-1.75$ & $<0.001$ & 1.47 & $1.25-1.73$ & $<0.001$ \\
\hline History of stroke & 2.49 & $1.47-4.19$ & 0.001 & & & \\
\hline History of heart failure & 2.04 & $1.13-3.68$ & 0.019 & & & \\
\hline Diuretics & 3.56 & $2.11-6.02$ & $<0.001$ & 2.29 & $1.34-3.92$ & 0.003 \\
\hline LAV index & 1.02 & $1.01-1.03$ & 0.005 & & & \\
\hline Significant FTR & 4.78 & $2.84-8.05$ & $<0.001$ & 3.62 & $2.11-6.21$ & $<0.001$ \\
\hline Impaired RV systolic function & 2.20 & $1.22-3.98$ & 0.009 & & & \\
\hline Pulmonary hypertension & 2.68 & $1.59-4.51$ & $<0.001$ & 2.10 & $1.22-3.60$ & 0.007 \\
\hline
\end{tabular}

Abbreviations: $C l$ confidence interval, FTR functional tricuspid regurgitation, $L A V$ left atrial volume, $R V$ right ventricular, $H R$ Hazard ratio

cumulative adverse outcomes after 2 years are higher. In this population, $44.6 \%$ of the patients had adverse outcomes, including heart failure (36.9\%) and death (12.3\%). Of note, the presence of $\mathrm{PH}$ worsens the prognosis of patients with significant TR [21].

There was no cardiac death over the two-year duration of the present study or the one-year duration of the previous study by Yakahashi et al. [7]. Apart from the short-term follow-up in these studies, the explanation may be, in part, due to a benign nature of FTR (unless associated with PH, RV or LV dysfunction) and the long duration of optimal treatment with medication. Even though there was no cardiac death, the present study found that heart failure was an important cardiovascular endpoint. Our findings demonstrated that heart failure occurred in $36.9 \%$ of AF patients with significant FTR over the course of 2 years. Previous studies have reported a poor prognosis in patients who have AF with heart failure, even with preserved LVEF [1]. This is true as well for patients with AF and persistent TR who required hospitalization for right-sided heart failure [7].
Predictors of significant functional tricuspid regurgitation in patients with atrial fibrillation

FTR has been described in a variety of cardiac disorders with RV remodeling and tricuspid annular dilatation [19, 23, 24]. AF leads to atrial enlargement and dilatation of mitral and tricuspid annuli [4]. Advanced age and right heart enlargement have been associated with atrial FTR $[8,18,20]$. Furthermore, some echocardiographic parameters are related to TR severity in patients with AF, such as LAV index, tricuspid annular diameter, tenting height, right atrial area, PASP and RV remodeling $[8,25]$. Apart from the echocardiographic parameters related to right heart remodeling, the present study demonstrated that female gender, LAV index and PH were independently associated with significant FTR in patients with AF. Left atrial enlargement and an increase in PAP reflect the non-right heart disease, which indirectly leads to FTR. Diastolic dysfunction is a common functional cardiac abnormality leading to left atrial enlargement and $\mathrm{PH}$,

Table 5 Univariate and multivariable analyses of the predictors of heart failure visit and hospitalization

\begin{tabular}{|c|c|c|c|c|c|c|}
\hline \multirow[t]{2}{*}{ Parameters } & \multicolumn{3}{|c|}{ Univariate analysis } & \multicolumn{3}{|c|}{ Multivariable analysis } \\
\hline & $\mathrm{HR}$ & $95 \% \mathrm{Cl}$ & $P$-value & $\mathrm{HR}$ & $95 \% \mathrm{Cl}$ & $P$-value \\
\hline Female gender & 4.04 & $1.89-8.63$ & $<0.001$ & 2.41 & $1.12-5.22$ & 0.025 \\
\hline $\mathrm{CHA}_{2} \mathrm{DS}_{2}$-VASc score & 1.32 & $1.10-1.58$ & 0.003 & & & \\
\hline History of stroke & 2.02 & $1.07-3.82$ & 0.030 & 2.05 & $1.06-4.0$ & 0.034 \\
\hline History of heart failure & 2.87 & $1.47-5.61$ & 0.002 & & & \\
\hline Diuretics & 5.86 & $3.11-11.07$ & $<0.001$ & 3.32 & $1.71-6.46$ & $<0.001$ \\
\hline LAV index & 1.03 & $1.01-1.04$ & $<0.001$ & & & \\
\hline Significant FTR & 7.08 & $3.70-13.54$ & $<0.001$ & 4.59 & $2.33-9.05$ & $<0.001$ \\
\hline Impaired RV systolic function & 2.75 & $1.39-5.44$ & 0.004 & & & \\
\hline Pulmonary hypertension & 3.87 & $2.04-7.37$ & $<0.001$ & 2.44 & $1.25-4.79$ & 0.009 \\
\hline
\end{tabular}

Abbreviations: $A F$ atrial fibrillation, $C l$ confidence interval, $F T R$ functional tricuspid regurgitation, $L A V$ left atrial volume, $R V$ right ventricular, $H R$ Hazard ratio 

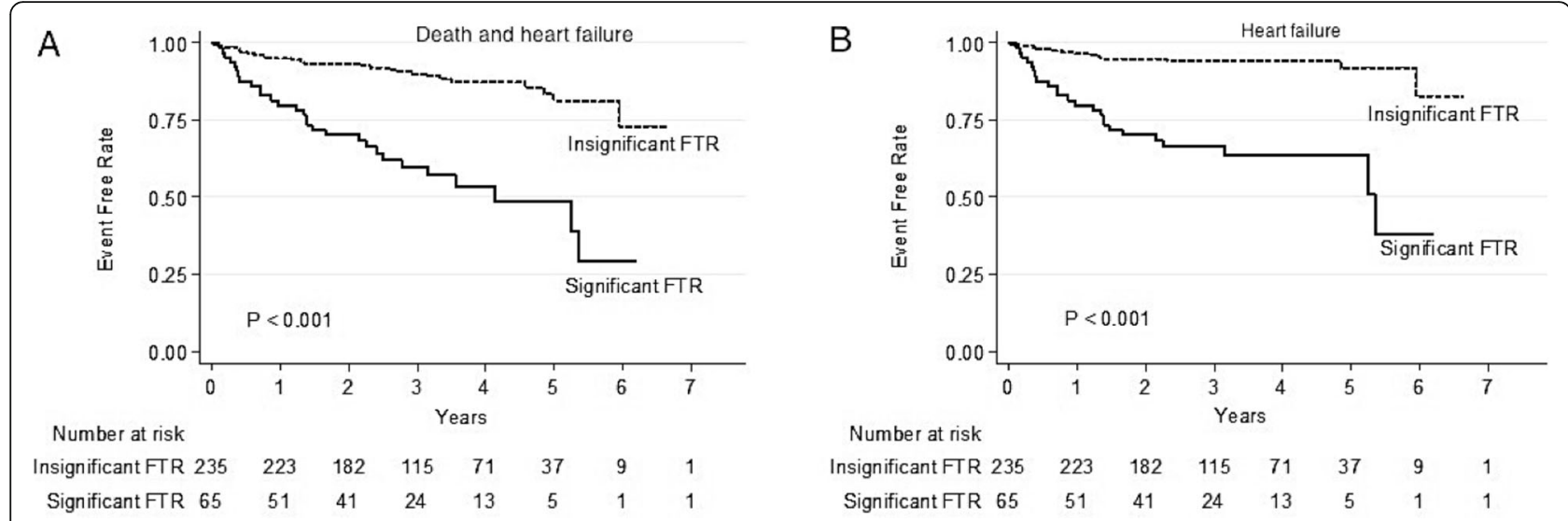

Fig. 1 Kaplan-Meier curves for the event-free rates from death and heart failure (a) and heart failure (b) in patients with atrial fibrillation, comparisons between those with significant and insignificant functional tricuspid regurgitation. FTR $=$ functional tricuspid regurgitation

and possibly FTR. However, further studies will be required to elucidate this causal relationship.

\section{Predictors of adverse outcomes in patients with atrial fibrillation}

The prognostic significance of significant FTR in patients with AF was previously described, and an increasing severity of TR was correlated with a worse outcome $[21,26]$. Data from a community-based study showed that AF in patients with heart failure and preserved LVEF portended a poor prognosis [1]. Significant FTR increased the probability of future episodes of heart failure in patients with AF [9]. In agreement with other studies, the present study showed that significant FTR was an independent predictor of adverse outcomes of heart failure and death. Furthermore, patients with significant FTR were more commonly found to have worse hemodynamic parameters, such as right atrial pressure, PAP, the presence of $\mathrm{PH}$ and impaired RV systolic function. These findings might help to explain the more adverse outcomes found in this group. Data from the present study suggest that significant FTR merits further study in an attempt to determine ways to decrease the incidence of significant FTR and thus to prevent the high incidence of adverse outcomes reported in the present study.

\section{Study limitations}

This was a retrospective study conducted in a single center. A larger, prospective, multicenter study of patients with AF should be encouraged to identify the accurate incidence of FTR and factors associated with adverse outcomes. Most of the measurements in this study were performed using two-dimensional echocardiography, which might be less accurate and less reproducible than three-dimensional echocardiography. Specifically, TR severity was routinely assessed using the vena contracta width, TR jet area or semiquantitatively by visual estimation. More accurate assessment of TR severity, such as proximal isovelocity surface area, should be performed. Due to the retrospective nature of the present study, the echocardiographic findings did not include the parameters of right heart remodeling and could not elucidate the causal relationship between AF and atrial FTR.

\section{Conclusions}

Significant FTR was common in patients with AF and associated with adverse outcomes. Female gender, LAV index and presence of $\mathrm{PH}$ were independent predictors of significant FTR, while high $\mathrm{CHA}_{2} \mathrm{DS}_{2}$-VASc score, significant FTR and presence of $\mathrm{PH}$ were independent predictors of the adverse outcomes in patients with AF and preserved LVEF.

\section{Abbreviations}

AF: Atrial fibrillation; FTR: Functional tricuspid regurgitation; LAV: Left atrial volume; LV: Left ventricular; LVEF: Left ventricular ejection fraction; PAP: Pulmonary artery pressure; PASP: Pulmonary artery systolic pressure; PH: Pulmonary hypertension; RV: Right ventricular;" $\mathrm{S}_{\text {TV: }}^{\prime}$ Peak systolic myocardial velocity of lateral tricuspid annulus; TAPSE: Tricuspid annular plane systolic excursion; TR: Tricuspid regurgitation

\section{Acknowledgements}

The authors are indebted to Herbert M. Swick, M.D. for the manuscript preparation and grammatical editing.

The abstract of the study has been accepted and recently presented at the 2020 European Society of Cardiology Congress.

\section{Authors' contributions}

NP, conceived the study, participated in study design and data collection, interpreted data, drafted and revised the manuscript; NR, conceived the study, participated in study design, analyzed and interpreted data, drafted and revised the manuscript; KK, performed statistical analysis and the interpretations of data. All authors read and approved the final manuscript.

Funding

Not applicable.

\section{Availability of data and materials}

The datasets used and/or analysed during the current study are available from the corresponding author on reasonable request. 


\section{Ethics approval and consent to participate}

The Siriraj Institutional Review Board approved the study (Certificate of Approval no. Si 171/2019) and agreed that the informed consent was not necessary due to the retrospective nature of the study. The information of all patients was anonymized and de-identified prior to analysis.

\section{Consent for publication}

Not applicable.

\section{Competing interests}

The authors declare that they have no completing interests.

\section{Author details}

'Division of Cardiology, Department of Medicine, Faculty of Medicine, Siriraj Hospital, Mahidol University, Bangkok 10700, Thailand. ${ }^{2}$ Department of Medicine, Faculty of Medicine, Siriraj Hospital, Mahidol University, Bangkok 10700, Thailand.

Received: 5 May 2020 Accepted: 27 September 2020

Published online: 06 October 2020

\section{References}

1. Zakeri R, Chamberlain AM, Roger VL, Redfield MM. Temporal relationship and prognostic significance of atrial fibrillation in heart failure patients with preserved ejection fraction: a community-based study. Circulation. 2013;128: 1085-93.

2. Chugh SS, Havmoeller R, Narayanan K, Singh D, Rienstra M, Benjamin EJ et al. Worldwide epidemiology of atrial fibrillation: a global burden of disease 2010 study. Circulation. 2014;129:837-47.

3. Wolf PA, Benjamin EJ, Belanger AJ, Kannel WB, Levy D, D'Agostino RB, Secular trends in the prevalence of atrial fibrillation: the Framingham study. Am Heart J. 1996;131:790-5.

4. Sanfilippo AJ, Abascal VM, Sheehan M, Oertel LB, Harrigan P, Hughes RA et al. Atrial enlargement as a consequence of atrial fibrillation. A prospective echocardiographic study. Circulation. 1990;82:792-7.

5. Zhou X, Otsuji Y, Yoshifuku S, Yuasa T, Zhang H, Takasaki K, et al. Impact of atrial fibrillation on tricuspid and mitral annular dilatation and valvular regurgitation. Circ J. 2002;66:913-6.

6. Muraru D, Guta AC, Ochoa-Jimenez RC, Bartos D, Aruta P, Mihaila S, et al. Functional regurgitation of Atrioventricular valves and atrial fibrillation: an elusive pathophysiological link deserving further attention. J Am Soc Echocardiogr. 2020;33:42-53.

7. Takahashi Y, Izumi C, Miyake M, Imanaka M, Kuroda M, Nishimura S, et al. Actual management and prognosis of severe isolated tricuspid regurgitation associated with atrial fibrillation without structural heart disease. Int J Cardiol. 2017;243:251-7.

8. Utsunomiya H, Itabashi Y, Mihara H, Berdejo J, Kobayashi S, Siegel RJ, et al. Functional tricuspid regurgitation caused by chronic atrial fibrillation: a realtime 3-dimensional transesophageal echocardiography study. Circ Cardiovasc Imaging. 2017;10:e004897.

9. Abe Y, Akamatsu K, Ito K, Matsumura Y, Shimeno K, Naruko T, et al. Prevalence and prognostic significance of functional mitral and tricuspid regurgitation despite preserved left ventricular ejection fraction in atrial fibrillation patients. Circ J. 2018;82:1451-8,

10. Ozlek B, Ozlek E, Tekinalp M, Kahraman S, Zencirkiran Agus H, Basaran O, et al. Comparison of clinical characteristics of patients with heart failure and preserved ejection fraction with atrial fibrillation versus sinus rhythm: insights from the APOLLON registry. Turk Kardiyol Dern Ars. 2020:48(3):234-45.

11. Kirchhof P, Benussi S, Kotecha D, Ahlsson A, Atar D, Casadei B, et al. 2016 ESC guidelines for the management of atrial fibrillation developed in collaboration with EACTS. Eur Heart J. 2016;37:2893-962.

12. Lang RM, Bierig M, Devereux RB, Flachskampf FA, Foster E, Pellikka PA, et al. Recommendations for chamber quantification: a report from the American Society of Echocardiography's guidelines and standards committee and the chamber quantification writing group, developed in conjunction with the European Association of Echocardiography, a branch of the European Society of Cardiology. J Am Soc Echocardiogr. 2005:18:1440-63.

13. Lang RM, Badano LP, Mor-Avi V, Afilalo J, Armstrong A, Ernande L, et al. Recommendations for cardiac chamber quantification by echocardiography in adults: an update from the American Society of Echocardiography and the European Association of Cardiovascular Imaging. J Am Soc Echocardiogr. 2015;28:1-39 e14.

14. Tribouilloy CM, Enriquez-Sarano M, Bailey KR, Tajik AJ, Seward JB. Quantification of tricuspid regurgitation by measuring the width of the vena contracta with Doppler color flow imaging: a clinical study. J Am Coll Cardiol. 2000;36:472-8.

15. Zoghbi WA, Enriquez-Sarano M, Foster E, Grayburn PA, Kraft CD, Levine RA, et al. Recommendations for evaluation of the severity of native valvular regurgitation with two-dimensional and Doppler echocardiography. J Am Soc Echocardiogr. 2003;16:777-802.

16. Zoghbi WA, Adams D, Bonow RO, Enriquez-Sarano M, Foster E, Grayburn $\mathrm{PA}$, et al. Recommendations for noninvasive evaluation of native Valvular regurgitation: a report from the American Society of Echocardiography developed in collaboration with the Society for Cardiovascular Magnetic Resonance. J Am Soc Echocardiogr. 2017:30:303-71.

17. Rudski LG, Lai WW, Afilalo J, Hua L, Handschumacher MD, Chandrasekaran K et al. Guidelines for the echocardiographic assessment of the right heart in adults: a report from the American Society of Echocardiography endorsed by the European Association of Echocardiography, a registered branch of the European Society of Cardiology, and the Canadian Society of Echocardiography. J Am Soc Echocardiogr. 2010;23:685-713.

18. Najib MQ, Vinales KL, Vittala SS, Challa S, Lee HR, Chaliki HP. Predictors for the development of severe tricuspid regurgitation with anatomically normal valve in patients with atrial fibrillation. Echocardiography. 2012;29:140-6.

19. Mutlak D, Lessick J, Reisner SA, Aronson D, Dabbah S, Agmon Y. Echocardiography-based spectrum of severe tricuspid regurgitation: the frequency of apparently idiopathic tricuspid regurgitation. J Am Soc Echocardiogr. 2007:20:405-8

20. Yamasaki N, Kondo F, Kubo T, Okawa M, Matsumura Y, Kitaoka H, et al. Severe tricuspid regurgitation in the aged: atrial remodeling associated with long-standing atrial fibrillation. J Cardiol. 2006;48:315-23.

21. Nath J, Foster E, Heidenreich PA. Impact of tricuspid regurgitation on longterm survival. J Am Coll Cardiol. 2004:43:405-9.

22. Ong K, Yu G, Jue J. Prevalence and spectrum of conditions associated with severe tricuspid regurgitation. Echocardiography. 2014;31:558-62.

23. Topilsky $Y$, Khanna A, Le Tourneau T, Park S, Michelena H, Suri R, et al. Clinical context and mechanism of functional tricuspid regurgitation in patients with and without pulmonary hypertension. Circ Cardiovasc Imaging. 2012:5:314-23.

24. Sagie A, Schwammenthal E, Padial LR, Vazquez de Prada JA, Weyman AE, Levine RA. Determinants of functional tricuspid regurgitation in incomplete tricuspid valve closure: Doppler color flow study of 109 patients. J Am Coll Cardiol. 1994;24:446-53.

25. Park JH, Shin SH, Lee MJ, Lee MD, Shim HI, Yoon J, et al. Clinical and echocardiographic factors affecting tricuspid regurgitation severity in the patients with lone atrial fibrillation. J Cardiovasc Ultrasound. 2015; 23:136-42.

26. Topilsky Y, Nkomo VT, Vatury O, Michelena HI, Letourneau T, Suri RM, et al. Clinical outcome of isolated tricuspid regurgitation. JACC Cardiovasc Imaging. 2014;7:1185-94.

\section{Publisher's Note}

Springer Nature remains neutral with regard to jurisdictional claims in published maps and institutional affiliations.

Ready to submit your research? Choose BMC and benefit from:

- fast, convenient online submission

- thorough peer review by experienced researchers in your field

- rapid publication on acceptance

- support for research data, including large and complex data types

- gold Open Access which fosters wider collaboration and increased citations

- maximum visibility for your research: over $100 \mathrm{M}$ website views per year

At BMC, research is always in progress.

Learn more biomedcentral.com/submission 